\title{
O "LUGAR" DA HISTÓRIA DA ÁFRICA E DAS AFRICANIDADES NO CURSO DE HISTÓRIA DA UNIVERSIDADE FEDERAL DO OESTE DO PARÁ (UFOPA): ENTRECRUZAMENTOS E SENSIBILIDADES*
}

\author{
Gustavo Pinto de Sousa ${ }^{1}$
}

\begin{abstract}
A luta pela justiça global deve, por isso, ser também uma luta pela justiça cognitiva global. Para ser bem-sucedida, esta luta exige um novo pensamento, um pensamento pós-abissal. (Santos, 2007, p. 2).
\end{abstract}

O sociólogo português Boaventura de Sousa Santos, no texto "Para além do pensamento abissal" (2007), conduz uma inquietante e provocativa reflexão a respeito da qualidade dos conhecimentos. Para ele, a modernidade ocasionou a distinção dos universos de pensamento. Classificadas como o "universo deste lado da linha" e o "universo do outro lado da linha", essas duas formas de entendimento colocam em cena as diferentes formas de leitura do mundo. Essas dualidades lembram as hierarquizações raciais entre os brancos, sapiente, europeus, em detrimento dos africanos, afro-americanos, indígenas ou de todo aquele não europeu.

Nessa perspectiva, o pensamento abissal configura-se como uma forma de ordenamento dos saberes. Nas palavras de Santos (2007, p. 2), "o pensamento abissal moderno salienta-se pela sua capacidade de produzir e radicalizar dis tinções". Em linhas gerais, a identificação de um pensamento abissal constrói uma normatização entre as sociedades modernas e os territórios coloniais (Santos, 2007); as primeiras, como lugar de excelência das produções científicas, acadêmicas e culturais, enquanto os outros, como locus do excêntrico, folclórico e alternativo.

*DOI - 10.29388/978-65-86678-64-2-0-f.101-118

${ }^{1}$ É graduado, mestre e doutor em História, com pesquisas nas áreas de história atlântica, tráfico intercontinental de escravos e ensino de história. Foi professor-assistente e, posteriormente, professor adjunto em História da África da Universidade Federal do Oeste do Pará (Ufopa). Atuou nessa universidade entre os anos 2014 e 2018, quando foi redistribuído para outro Instituto de Ensino Superior (IES). Atualmente, é professor adjunto no Departamento de Ensino Superior no Instituto Nacional de Educação de Surdos (Desu/Ines) e coordenador da linha de pesquisa sobre Áfricas e suas diásporas no Laboratório de Estudos das Diferenças e Desigualdades Sociais da Universidade do Estado do Rio de Janeiro (Leddes/Uerj). 
Assim, o outro lado da linha é o ponto de partida da reflexão e existência do lugar da história da África e das africanidades no curso de história da Universidade Federal do Oeste do Pará (Ufopa). Pensar as africanidades como expressão antropológica e discursiva de compreensão dos "modos de ser, de viver, de organizar suas lutas" (Silva, 2005, p. 155), suas tradições e códigos culturais do ser africano e africana em sua pluralidade. Uma definição próxima ao que Petronilha Beatriz Gonçalves e Silva (2005, p. 155) observou ao estudar as africanidades brasileiras.

Nesse sentido, nas palavras de Boaventura de Sousa Santos:

Do outro lado da linha, não há conhecimento real; existem crenças, opiniões, magia, idolatria, entendimentos intuitivos ou subjetivos, que, na melhor das hipóteses, podem tornar-se objeto ou matéria-prima para a inquirição científica. Assim, a linha visível que separa a ciência dos seus "outros" modernos está assente na linha abissal invisível que separa[,] de um lado, ciência, filosofia e teologia e, do outro, conhecimentos tornados incomensuráveis e incompreensíveis por não obedecerem, nem [a]os critérios científicos de verdade, nem aos dos conhecimentos, reconhecidos como alternativos, da filosofia e da teologia. (Santos, 2007, p. 4).

Insurgir contra essa linha abissal do conhecimento, que elege um espaço de construção do conhecimento, tem sido a função das universidades interiorizadas pelo governo do ex-presidente Luiz Inácio Lula da Silva e também das universidades das capitais. Em linhas gerais, o texto percorrerá uma análise de como o projeto político-pedagógico do curso, especificamente a licenciatura em história, e as discussões das ementas do curso procuraram conduzir as disciplinas de história da África e as africanidades para um horizonte pós-abissal. E por que pós-abissal?

A luta pós-abissal é um combate por uma história entrecruzada, não hierárquica, das sensibilidades e das identidades. É um empenho de disciplinas inclusivas, dialógicas e que façam esparzir conhecimentos. É uma ecologia dos saberes, conforme propõe Boaventura de Sousa Santos, em que é preciso romper as linhas abissais que separam os "lugares oficiais" de conhecimento dos "lugares oficiosos e não formais". Uma ecologia dos saberes para trazer os conhecimentos de fora para dentro, não como um mero espaço de empiria, mas como forma de agregar, valorizar e interagir.

A justiça social global é um campo de embate por uma autonomia cognitiva do conhecimento e dos sujeitos. E, no Brasil de 2019, a possibilidade de defender uma autonomia cognitiva assusta os setores conservadores, racistas e 
reacionários da sociedade brasileira, que por anos silenciaram e oprimiram aqueles que hoje rompem com as linhas de um conhecimento abissal. Questionar uma identidade essencializada, monocromática e cristalizada tem sido o desafio daqueles que acreditam ser necessária uma pedagogia da autonomia do conhecimento (Freire, 2013). É nesse contexto que a função social e acadêmica da Ufopa precisa ser debatida.

Criada em 5 de novembro de 2009, a Ufopa surgiu da separação do campus de Santarém, que pertencia à Universidade Federal do Pará (UFPA), e da unidade Tapajós, da Universidade Federal Rural da Amazônia (UFRA). Hoje, a Ufopa conta com seis campi: Alenquer, Itaituba, Juruti, Monte Alegre, Óbidos e Oriximiná. Sua sede fica na cidade de Santarém, com três unidades: Amazônia, Tapajós e Rondon; na última, funciona o curso de licenciatura em história.

Em seu Plano de Desenvolvimento Institucional (PDI) (Ufopa, 20122016), sob a administração da ex-reitora Raimunda Nonata Monteiro, a Ufopa apresentava três pilares para as referências estratégicas da instituição, que são:

Missão: "Produzir e socializar conhecimentos, contribuindo para a cidadania, inovação e desenvolvimento na Amazônia." Visão: "Ser referência na formação interdisciplinar para integrar sociedade, natureza e desenvolvimento." Valores: respeito; pluralismo; responsabilidade social e ambiental; transparência; identidade institucional; interdisciplinaridade; lealdade; profissionalismo; inclusão; ética. (Ufopa, 2015, p. 29-30).

O PDI é um documento institucional que organiza o desenvolvimento, os objetivos e as funcionalidades da universidade, em consonância com as demandas da sociedade e da realidade local. É um exercício peculiar pensar a localidade da Ufopa, que fica em uma urbe no interior da Amazônia. Neste ponto do texto, faço uma pausa para discorrer, de maneira resumida, sobre a realidade da cidade de Santarém, localizada no Baixo Amazonas.

Santarém é um espaço onde passado e presente entrecruzam-se cotidianamente. São homens, mulheres e crianças das margens dos rios, os ribeirinhos e ribeirinhas, os remanescentes das comunidades quilombolas, filhos da terra, os migrantes e os imigrantes. Por um lado, há a vida dos pescadores, da cultura artesanal, e, por outro, os grandes hectares das plantações de soja, que nos despertam para a vigilância em prol da sustentabilidade na Amazônia. Uma cidade que vive as tradições temporais — círios, sairé e procissões — ao lado de um espaço que cede ambientes para outras representações dos chamados grandes centros urbanos, como grandes shows. 
Reflexões e existência: universidade pública e a formação de professores de história no interior da Amazônia, organizado por André Fonseca e Lorena Lopes, é um exercício de pensar essa realidade. Empossado na Ufopa em setembro de 2014, chego à instituição como professor do magistério superior. Migrante da cidade do Rio de Janeiro, onde trabalhei na rede estadual e privada de ensino, a Ufopa seria um novo desafio para um docente.

As primeiras turmas nas quais lecionei faziam parte da extinta Licenciatura Integrada em História e Geografia e da Pedagogia. Foram estas: Educação e Relações Étnico-raciais (turma composta por discentes de todas as licenciaturas), Fundamentos Teórico-práticos em História (Pedagogia) e História da África II (História). Posteriormente, passei pelas cadeiras de História da África I e Brasil II, e, por último, por uma disciplina eletiva sobre Tópicos de Estudo em História: Temas Sensíveis, Histórias Cruzadas. Além disso, o curso de história era responsável por ofertar disciplinas no Plano Nacional de Formação de Professores da Educação Básica (Parfor), que levava para os municípios interioranos da região do Baixo Amazonas a Licenciatura Integrada em História e Geografia. No Parfor, fiquei responsável pelas disciplinas Estágio Supervisionado em História, Prática de Ensino em História e História da América I.

Nesse exercício da escrita de si, como sugere Michel Foucault (1992), sujeitos e identidades estabelecem uma inter-relação, uma vez que, para o filósofo, essa dinâmica pode ser um questionamento da identidade. $\mathrm{E}$ as aulas nos cursos de formação de professores da Ufopa conduziram para essa realidade de inquirir sobre a prática docente. Com todo respeito à produção historiográfica nacional, os cursos de licenciatura registram suas bases teóricas e metodológicas com referências aos autores do Sudeste brasileiro. Grosso modo, os centros de estudos em São Paulo e no Rio de Janeiro formaram parcela considerável dos professores em exercício nas universidades do país.

O motivo para essa questão é de fácil visualização, uma vez que a maior parte dos cursos de pós-graduação - mestrado e doutorado - concentra-se em cidades do Sudeste. E, em relação à região Norte, esses cursos eram escassos e dedicados aos trabalhos de uma escrita de história regional. Em 2019, o estado do Pará, na área da pós-graduação em história, conta com o curso de mestrado e doutorado da UFPA, um mestrado profissional na Universidade do Estado do Pará (Uepa) e o recém-inaugurado Programa de Pós-graduação em História da Universidade Federal do Sul e Sudeste do Pará (Unifesspa). Todavia, o objeto deste texto não é discutir a distribuição da pós-graduação no Brasil, mas, sim, como essa formação acadêmica implicaria o curso de licenciatura em história. 
Logo nas primeiras aulas, pude perceber que a realidade pedagógica da Ufopa era diferente da que eu conhecia no Rio de Janeiro. Uma semelhança entre as duas localidades era a étnico-diversidade encontrada em sala de aula. Se, na Cidade Maravilhosa, eu encontrava homens, mulheres e jovens de diferentes classes sociais, gêneros e etnias, na Pérola do Tapajós não haveria de ser diferente. Entretanto, uma diferença despertava minha curiosidade: a presença dos alunos e das alunas indígenas na universidade. Em 2003, vivi a aprovação da Lei no 10.639 pelo ex-presidente Lula, que trazia a obrigatoriedade do ensino de história da África e da cultura afro-brasileira nos currículos da Educação Básica.

Passados sete anos, a ex-presidenta Dilma Rousseff alterava a Lei $\mathrm{n}^{\circ}$ $10.639 / 2003$ e promulgava a Lei no $11.645 / 2009$, que mudava a primeira e incluía a obrigatoriedade do ensino de história e cultura indígena nos currículos escolares. E, a partir de 2014, a Lei no 11.645/2009 tomou um sentido diferente em minha prática docente e na forma de atuação nos cursos de formação de professores. Em um estudo sobre os estudantes indígenas na Ufopa, Diego Marinho e Eveline de Sousa discutem como a experiência desses alunos somam-se ao cotidiano da universidade. Segundo eles:

Para os estudantes indígenas, o processo de entrar na Ufopa não se restringe apenas ao aspecto educacional e às formas de conhecimento, mas também representa uma mudança tanto nas suas vidas quanto na vida de suas famílias. A maioria deles vive em comunidades rurais, nas áreas ribeirinhas e na selva do Baixo e Médio Tapajós, no rio Arapiuns e na Calha Norte. (Marinho e Sousa, 2017, p. 115, tradução nossa).

Toda essa transformação entre os alunos indígenas, e incluiria também os quilombolas, conduziu-me a (re)pensar e a (re)inventar a prática docente. Nesse momento, Os estabelecidos e os outsiders, de Norbert Elias e John Scotson (2000), emergiu em meu comportamento. Se os primeiros eram os indivíduos pertencentes ao grupo social em questão, os últimos eram os estrangeiros. Em relação ao espaço da sala de aula, os waiwais, arapiuns e tupinambás não eram os únicos na condição de exterioridade daquela realidade. E, para nos complementarmos, era necessária uma integração.

Descrevo uma pequena cena: turma da manhã de história, 2014. Começava minha aula sobre imperialismo, colonização e assimilação com Franz Fanon - Pele negra, máscaras brancas (2008) —, discutindo com os alunos sobre os mecanismos da conquista e da violência simbólica da assimilação. Em meio ao 
debate caloroso, que a turma de 2014 conduzia, olhei para dois alunos indígenas e perguntei: o que vocês estão entendendo do assunto?

Tímidos, os alunos esforçaram-se para responder à questão. Logo se notou que sua retração era tomada por certa insegurança da língua portuguesa. Afinal, esses discentes desenvolvem, além da formação do curso de história, uma educação bilíngue: têm a língua de origem como L1 e o português como L2. Não satisfeito com a resposta deles, resolvi provocá-los e inverter a questão. Se antes questionava: "o que vocês acham do processo de assimilação que os africanos sofreram pelos europeus?", apresentei: "na aldeia de vocês já aconteceu algo parecido?”. Pronto! O grupo de alunos indígenas começou a responder, a comparar e a entrecruzar informações.

Guardadas as devidas comparações, a fim de evitar os radicalismos e os etnocentrismos, os indígenas relatavam como a perspectiva assimilacionista condenava suas práticas cotidianas, desde os modos de vestir até sua relação com a natureza e a religião. Assim, a psicologia do branco europeu e do negro africano de Pele negra, máscaras brancas (2008) aos poucos se tornava pele indígena, máscaras brancas, na melhor comparação com Fanon. As atrocidades do período colonial africano iam aos poucos sendo inscritas no cotidiano dos estudantes indígenas do curso de história da Ufopa.

Essa experiência pedagógica levou-me a (re)visitar José Carlos Libâneo, em seu livro Didática (2013). Segundo ela, os pedagogos acreditam que o conhecimento acadêmico-científico pode ser transformado em conhecimento escolar. Em linhas gerais, essa transformação não assume caráter hierárquico, mas de metamorfose para as realidades pedagógicas. A transposição didática consiste nisto: "o trabalho que transforma um objeto de saber ensinar em um objeto de ensino é denominado Transposição Didática” (Chevallard, 1991, p. 45).

Em suma, há um saber científico (acadêmico), resultado de pesquisas e inquietações e que é palco nas discussões universitárias. Por outro lado, esse saber é problematizado pelos licenciandos e professores da Educação Básica como forma de transformação. O saber ensinar conduzido pelos professores da Educação Básica é o ponto de interação das realidades — acadêmicas e escolares —, pois é o docente da Educação Básica, a partir de suas diferentes ferramentas metodológicas e pedagógicas, o responsável pela transformação do saber que se tornará objeto das salas de aula, ou seja, o saber ensinado que chega aos alunos e alunas nas cenas escolares.

$\mathrm{Na}$ escrita da história sobre o ensino de história, os autores costumam tratar da transformação do conhecimento a partir das noções de saber acadêmico e saber escolar. Kátia Maria Abud, no artigo "A história nossa de cada dia" 
(2007), pensa a história como disciplina escolar, inter-relacionando o Colégio Pedro II e o Instituto Histórico e Geográfico Brasileiro (IHGB). Abud toma como objeto de análise a história nacional produzida no IHGB — saber acadêmico - e a história nacional no âmbito escolar do Colégio Pedro II — saber escolar. A autora conclui que, entre o IHGB e o Colégio Pedro II, estabeleceuse uma relação de disseminação e instrumentalização do saber, pois, se o primeiro debatia, academicamente, a construção da nacionalidade brasileira pela questão racial, mesológica e climática - Karl von Martius, Adolfo de Varnhagen, Januário da Cunha Barbosa -, o segundo desdobrava nos manuais didáticos a importância do ser brasileiro e da grandiosidade do Brasil, conforme o livro didático de Manuel Joaquim de Macedo intitulado Lições de história do Brasil para uso dos alunos do Imperial Colégio de Pedro II (1861).

No horizonte da história pública, Jörn Rüsen apresenta essa transformação do conhecimento pela concepção de didáticas da história. Em seu texto "Didática da história" (2006), a noção de didática da história discutida por ele conflita com as colocações de Libâneo. Para ele, é limitada a afirmação de que "a didática da história serve como uma ferramenta que transporta conhecimento histórico dos recipientes cheios de pesquisa acadêmica para as cabeças vazias dos alunos” (Rüsen, 2006, p. 8). Rüsen acredita que a função da didática da his tória seria

[...] investigar o aprendizado histórico. O aprendizado histórico é uma das dimensões e manifestações da consciência histórica. É o processo fundamental de socialização e individualização humana e forma o núcleo de todas estas operações. A questão básica é como o passado é experienciado e interpretado de modo a compreender o presente e antecipar o futuro. [...] Ele determina a significância do assunto da história da didática bem como suas abordagens teóricas e metodológicas específicas. (Rüsen, 2006, p. 271).

Para o teórico alemão, a didática da história não se vale apenas dos métodos estritos da história, mas utiliza ferramentas da psicologia, da sociologia e da comunicação social, e, em tempos de novas mídias, essas ferramentas são usadas como uma forma de reflexão da consciência histórica. Em linhas gerais, "a didática da História ou ciência do aprendizado histórico pode demonstrar ao historiador profissional as conexões internas entre história, vida prática e aprendizado" (Rüsen, 2006, p. 271). Portanto, em Rüsen há uma preocupação de que o ensino de história leve os alunos e as alunas à conscientização histórica e, eu me arriscaria a dizer, da realidade que os rodeia. 
Transposição didática, saber acadêmico, saber dos professores, saber escolar, didáticas da história e história pública - muitas eram as ferramentas diante da realidade da educação superior do curso de história da Ufopa. E uma questão emergia: como todas as discussões poderiam exercer influência em minha sala de aula e na formação de professores? Transportá-las e adaptá-las não seria o suficiente. Havia um conflito maior: entre o saber de um professor formado nas universidades do Sudeste e uma realidade e novos atores na cidade de Santarém. Era preciso uma hibridação e sensibilidades. Com relação à primeira, como afirma Nestor Canclini (2015, p. 38), "a hibridação não é sinônimo de fusão sem contradição, mas[,] sim, que pode ajudar a dar conta de formas particulares de conflitos geradas pela interculturalidade". Culturas híbridas são uma forma de ativar a alteridade, e não pulverizá-la em um conflito bélico cultural. São uma forma de fomentar novas estruturas ou identidades, mesmo que geradas pelo conflito.

E quanto às últimas? As sensibilidades não são menos importantes, embora muitas vezes relegadas pelos historiadores e, por que não dizer, pelos professores em geral. É difícil sentir o outro, com certeza. Mas é possível estudá-lo, principalmente em sala de aula. Em tempos de "menino veste azul e menina veste rosa", o estudo das sensibilidades é um refúgio contra todo silenciamento identitário que grupos limitados tentam impor aos diferentes protagonistas brasileiros. Por sensibilidades, Sandra Jatahy Pesavento entende:

As sensibilidades são sutis, difíceis de capturar, pois se inscrevem sob o signo da alteridade, traduzindo emoções, sentimentos e valores que não são mais os nossos. [...] uma estrangeiridade com relação ao que se passou por fora da experiência do vivido. (Pesavento e Langue, 2007, p. 15).

As sensibilidades não são formas de transferência do sentir. Pelo princípio filosófico da idiossincrasia, o sujeito não experimenta, da mesma maneira e com a mesma intensidade, os sentimentos, as emoções e as dores dos outros. Uma história das sensibilidades contribui para compartilhar sensações, possibilitando exercitar o lugar do outro. É isso, e não poderia ser diferente nos programas e nos planejamentos das disciplinas História da África, Brasil Império, Práticas de Ensino e Estágios, bem como na eletiva. Os discentes e eu não fugimos da historiografia das disciplinas, mas queríamos enxergar onde estava o permitir-se das sensibilidades ao analisar os contextos específicos. 
Portanto, no próximo tópico passo a analisar como essas orientações pedagógicas alteraram, transformaram e redimensionaram reflexões e existências nas disciplinas História da África e História das Africanidades.

\title{
Que história é essa? As Áfricas e as africanidades nos planejamentos de ensino
}

\author{
Brasil, meu nego \\ deixa eu te contar \\ a história que a história não conta \\ o avesso do mesmo lugar \\ na luta é que a gente se encontra. \\ (G.R.E.S. Estação Primeira de Mangueira, 2019).
}

No ano 2019, a Verde e Rosa do carnaval carioca levou para a avenida o enredo Histórias para ninar gente grande. O carnavalesco Leandro Vieira contou na Marquês de Sapucaí a história silenciada, subalternizada, ou as "páginas ausentes", como ele mesmo descreveu. Foi um movimento de narrar uma história que a própria história oficial não conta. E por que não conta? Porque a narrativa da história passa por uma questão de poder. Como escreveu Keith Jenkins (1995), a narrativa histórica perpassa pelas relações de poder, afinal oficializados e vulnerabilizados têm formas diferentes de relatar suas histórias.

Se, na história oficial do Brasil, há tantos vulnerabilizados, na história da África não seria diferente encontrar os mesmos silenciamentos. Carlos Lopes, em "A pirâmide invertida" (1995, p. 6), lembrava a afirmação do filósofo alemão Hegel de que a África não tem história, ou melhor, "da inexistência do fato histórico antes da colonização". Ou seja, antes da presença europeia no continente africano, a região vivia uma infantilidade ou uma menoridade do pensamento, como sugeriam filósofos iluministas como Hegel e também Kant (Lopes, 1995, p. 6).

Mas a história não é estática e muito menos uma verdade absoluta. Com a afirmação dos movimentos sociais, principalmente pelas associações de luta pelos direitos civis dos negros norte-americanos, pelas lutas libertárias na África na segunda metade do século XX, o Movimento Negro no Brasil, entre demais pautas sociais, outras formas de narrar a história foram ocupadas por esses personagens antes subalternizados. No Brasil, a aprovação da Lei $\mathrm{n}^{\mathrm{o}}$ 10.639/2003 antes de uma vitória política foi uma conquista do Movimento 
Negro Unificado (MNU), que, desde a década de 1980, lutava por outra narrativa dos africanos(as) e afro-brasileiros(as) na história dos Brasis e das Áfricas.

A Lei no 10.639/2003 não trouxe a obrigatoriedade do ensino de história da África e da cultura afro-brasileira apenas para as disciplinas da Educação Básica. Monica de Souza Lima discorre que essa lei teve amplitude ao envolver também as universidades brasileiras. Para ela:

[...] o Conselho Nacional de Educação colocou a público as Diretrizes Curriculares Nacionais para a Educação das Relações Étnico-Raciais e para o Ensino de História e Cultura Afro-Brasileira e Africana e, em junho daquele mesmo ano, aprovou a resolução no 17 , a qual, sem deixar margem a dúvidas, estabeleceu que as medidas diziam respeito também aos docentes e gestores do ensino universitário. (Lima, 2014, p. 3).

A Lei $\mathrm{n}^{\circ}$ 10.639/2003 e as Diretrizes Curriculares Nacionais para a Educação das Relações Étnico-raciais demandam um envolvimento de professores para o aprofundamento e a consolidação de campos de pesquisa, ensino e extensão que possam habilitar os docentes para uma nova forma de ensinar a história das Áfricas: não mais eurocêntrica, subdesenvolvida e periférica, mas protagonista de suas ações. Como consequência da lei, surgem nas universidades novos concursos docentes para essa disciplina, uma autonomia da disciplina, isto é, uma valorização do componente dentro dos currículos. Ademais, destaca-se a aquisição de algumas páginas nos livros escolares e nas estantes de livraria, cinema e, por que não falar, na valorização da moda e da estética.

Aprovado em 2017, o projeto político-pedagógico do curso de licenciatura em história da Ufopa traz três disciplinas para atendimento das demandas da história da África. São elas: História da África I e II, com carga horária de 85 horas cada, e uma disciplina eletiva de Estudos Temáticos em História da África, com carga horária de 60 horas, nas quais o docente tem liberdade de cátedra para ministrar conteúdos sobre história da África oriundos de pesquisas. Os chamados saberes em história da África fazem com que o curso de história da Ufopa ofereça aos alunos uma carga horária significativa de 230 horas de atividades de ensino.

O curso, pioneiro, foi recentemente comparado com os das demais universidades públicas no estado do Pará. Há, nesse curso de história, um avanço das discussões da Lei no 11.645/2008 a respeito da inclusão da história da África, afro-brasileira e da cultura indígena nos currículos. No texto "Balanços, comparações e sensibilidades: o lugar da Lei n. 11.645/2008 nas universidades 
públicas do Pará” (Gois e Sousa, 2019), Diego Marinho de Gois e eu constatamos, a partir da análise dos diferentes projetos pedagógicos de cursos (PPCs), que o curso de licenciatura em história da Ufopa dedica 305 horas-aula para atender à lei (Gois e Sousa, 2019).

Em uma licenciatura na qual os discentes precisam concluir 3.470 horas, as disciplinas provenientes da legislação educacional (Lei nํ 11.645/2008) ocupam $8,7 \%$ da grade curricular, sendo $6,2 \%$ de componentes curriculares em saberes em história da África. Mas qual história essas disciplinas buscam problematizar? Na ementa da disciplina História da África I, no sétimo período do curso, o documento traz como objeto de preocupação a seguinte descrição:

A escrita da História e a História da África; África antiga e medieval; Política e cultura na África saariana e o Islamismo em África; A modernidade e África. Escravidão como instituição africana. História Atlântica. Comércio trans/intercontinental: conflitos escravistas. Desarticulação do tráfico de escravos. África e Ensino de História. (Ufopa, 2017, p. 67).

A preocupação desse agrupamento é apresentar, na primeira disciplina de África do curso, os aspectos da história da África entre o período da Antiguidade africana e a interação da África nos quadros do desencravamento planetário. Levam-se em consideração também os métodos e as técnicas de pesquisa para história da África. Essa abordagem nos programas de história da África direciona-nos para a produção de uma escrita da história africana.

Há uma discussão de uma história da África que mescla os fatores endógenos e exógenos das questões africanas e que se renova ao dar voz a como os africanos e africanas entendem os processos históricos. Já a disciplina História da África II traz como base as seguintes discussões:

Historiografia Geral do continente africano no final do século XIX e século XX. Colonialismo, imperialismo e assimilação. Cultura e etnocentrismo. Movimentos de independência e construção da nação. Pós-colonialismo, nação e literatura. PALOPS (Países Africanos de Língua Oficial Portuguesa); África Contemporânea e Ensino de História: técnicas, métodos e possibilidades para o Ensino de História. (Ufopa, 2017, p. 69).

Já na disciplina História da África II, no oitavo período, há um estudo da África em finais do século XIX e no século XX. Inicia-se com a Conferência de Berlim, em 1885, e as lutas de independência pelas Áfricas durante o século XX. Nesse sentido, as temáticas de imperialismo, assimilação, crioulidade, naci- 
onalismos na África, independência, nacionalismos, pós-independência, globalização e novas identidades predominam na ementa.

Uma observação precisa ser feita sobre a organização curricular dos conteúdos. O grupo dos professores do Núcleo Docente Estruturante (NDE) optou por um currículo temporal em relação às disciplinas, ou seja, há uma cronologia nas disciplinas História da África I e II. Entretanto, como lembra Circe Bittencourt (2006, p. 12), o currículo é um documento que sofre modificações de acordo com a realidade de ensino. As diferenças entre um currículo pré-ativo - "normativo e escrito pelo poder educacional instituído" - e um currículo como prática - aquele que acontece em sala de aula - são resultados das subjetividades e da autonomia pedagógica dos professores, dos alunos e da realidade da comunidade escolar.

Nesse sentido, as disciplinas não ficam reféns apenas das ementas. Elas se transformam nas salas de aula, de acordo com as subjetividades de docentes e discentes. Ademais, nas disciplinas de 85 horas do curso, existe a proposta de que 25 horas sejam dedicadas às atividades ou propostas de ensino, uma vez que é um curso voltado à formação de professores (Ufopa, 2017, p. 99). Assim, a disciplina subdivide-se entre a leitura acadêmica e a experimentação de projetos de ensino que sirvam como referência para os futuros professores formados na Ufopa.

Mas que história é essa? Ou melhor, quem são os autores e autoras que os graduandos em história da Ufopa têm como referência em relação à história da África? Gois e eu (Gois e Sousa, 2019), ao analisarmos os ementários das disciplinas de história da África, percebemos que houve a preocupação em entender a África pela África, e não a história de um continente a partir de apêndices de outras histórias. Verificamos uma história da África feita por africanos e africanas, e demais pesquisadores e pesquisadoras sensíveis às particularidades das múltiplas historicidades daquele continente.

No primeiro componente africano, visualizam-se John Fage, Joseph Zi-Zerbo, Leila Hernandez, Luiz Felipe de Alencastro, Nicolas Grimal, Elikia M’Bokolo, Elisa Nascimento e Luiz Carlos Gá e Alberto da Costa e Silva. As obras referenciadas no ementário discutem os aspectos teórico-metodológicos nas pesquisas em história da África, a invenção e a discussão do Egito como civilização africana e o mito de uma civilização branca, questões de filosofia e cultura africana, a inter-relação e a presença da África na história atlântica, e, por fim, como abordar o ensino de história da África para os currículos da Educação Básica. 
Já em relação ao planejamento docente da disciplina ou a seu currículo como prática, isto é, aquele entregue pelo docente tendo como objetivo a discussão com os discentes da possibilidade de aplicá-lo, percebe-se a presença de outros autores, como: Carlos Lopes, Mario Maestri, Luis Beltan, José Rivair Macedo, Jorge Arturo Escalante, John Thorthon, Paul Lovejoy, Gustavo Sousa, Monica Lima, Martha Abreu e Hebe Mattos. Em linhas gerais, os textos discutem as renovações historiográficas em relação à produção de história da África (Carlos Lopes); a condição da África pré-colonial e a expansão do Islã pelo continente (Mário Maestri, Luis Beltan e José Rivair Macedo); a importância do griô como historiógrafo ou responsável pela transmissão do conhecimento (Jorge Arturo Escalante); as complexidades da história atlântica (John Thorthon, Paul Lovejoy e Gustavo Sousa); e as análises da importância dos estudos de história da África e cultura afro-brasileira (Monica Lima, Hebe Mattos e Martha Abreu).

O programa também conta com a análise e o debate de filmes, a saber: Kiriku e a feiticeira (1998) e Amistad (1997). A cinematografia é utilizada como fonte para o exercício de entrecruzamento entre a leitura acadêmica e a construção da narrativa visual. Ademais, o curso conta com três propostas avaliativas: a construção de seminários e intermediações; uma prova escrita; e a elaboração de um plano de aula sobre as temáticas levantadas no desenvolvimento da disciplina. A última tem o objetivo de atingir a proposta de ensino da disciplina e ser um fomento para atividades nas disciplinas Prática de Ensino e Estágio Supervisionado.

O segundo componente de história da África não foge da estrutura da primeira disciplina. No ementário, figuram Anthony Appiah, Valentim Alexandre, Marcelo Bittencourt, Henri Brunschwig, José Luis Cabaço e Henry Wesseling. As obras referenciadas no ementário discutem o pensamento contemporâneo dos autores africanos, principalmente seus expoentes no século XX; as raízes dos colonialismos que se fizeram presentes na África no fim do século XIX e início do século XX; os diferentes movimentos de independência no continente africano; a emergência dos nacionalismos; e as invenções das tradições e identidades na África independente.

Já em relação ao planejamento docente da disciplina, nota-se o debate a partir de alguns autores: Eric Hobsbawm, Albert Adu Boaben, Frantz Fanon, Anderson Oliva, Petronilha Beatriz Gonçalves e Silva, Murilo Sebe Meihy, Maurício Parada, Pablo de Oliveira Mattos, Edson Borges, Sílvio de Almeida Carvalho Filho, Ali Mazrui e Christope Wonde. 
Os textos discutem os desdobramentos dos diferentes colonialismos na África e seus instrumentos físicos e alusivos de dominação (Eric Hobsbawm e Albert Adu Boahen); a assimilação, a violência simbólica e a condição da psicologia africana (Frantz Fanon); as relações da África com o Brasil, a África no Brasil e as africanidades (Anderson Oliva e Petronilha Beatriz Silva); os processos de independência nas Áfricas — África do Norte, África Ocidental, África Central, África do Sul (Murilo Sebe Meihy, Maurício Parada e Pablo de Oliveira Mattos); os países africanos de língua oficial portuguesa (Sílvio de Almeida Carvalho Filho e Edson Borges); e, por fim, os desafios da África nos anos 1990 (Ali Mazrui).

O programa segue com a análise e o debate de filmes, a saber: Invictus (2009) e Uma lição de vida (2010). Assim como no primeiro componente, o curso conta com três propostas avaliativas: a construção de seminários e intermediações; uma prova escrita; e a elaboração de um livro paradidático destinado ao Ensino Fundamental II ou ao Ensino Médio que contemple algum dos tópicos trabalhados durante a disciplina. É importante, na organização dos paradidáticos, como projeto de ensino, que os discentes apresentem fontes históricas, a apropriação da historiografia e da metodologia, e uma linguagem adequada para a modalidade de ensino escolhida.

Portanto, o curso de licenciatura em história da Ufopa tem contemplado as discussões sobre as Áfricas e as africanidades, conforme determina a legislação educacional, não como mera formalidade legal e acadêmica. $\mathrm{O}$ curso faz um esforço em promover a história da África como componente obrigatório e ainda oferta a disciplina a todos os alunos e alunas de outros cursos da universidade que tenham interesse em discutir as temáticas africanas. Ademais, a disciplina opera em uma diretiva de mostrar a história que a história não conta. É colocar às avessas uma história que se apresenta como branca, masculina e eurocêntrica.

Por fim, a história da África e da cultura africana e afro-brasileira emerge como forma de ecologia dos saberes, pois trouxe para dentro da universidade e das escolas de Educação Básica novas formas de conhecimento, de ação, de estética e de pensamento em geral. A justiça global cognitiva é conectar todos es ses saberes em benefício de dilemas tanto educacionais quanto sociais. Uma ecologia dos saberes não atende apenas a um projeto multiculturalista ou pósmoderno, conforme classificam os críticos, mas se faz necessária para dar vozes àqueles que por anos foram subalternizados. 


\section{Considerações contínuas...}

Não saberia terminar este texto no rigor formal de considerações finais. Apesar de não ser mais docente ativo da licenciatura em história da Ufopa, trago sua identidade em minha prática docente. Como diria minha querida professora e orientadora Marilene Rosa (in memoriam), "nós afetamos e somos afetados". Afetividade por alguns amigos docentes, alunos e alunas. Afeto, como verbo e adjetivo, são ações e qualidades que nos sensibilizam perante a realidade. Hoje, como professor do Instituto Nacional de Educação de Surdos (Ines), no Rio de Janeiro, todos esses questionamentos se repetem. É claro, com novas problematizações.

O desafio no Ines tem sido aprender o universo da língua brasileira de sinais (Libras) e como posso contribuir para a inserção da Lei no 11.645/2008 no âmbito da cultura bilíngue. Não é à toa que, neste texto, faço referência à L1 e à L2. E descobri que sou L1 em língua portuguesa, enquanto aprendo minha L2 em Libras. No Ines, tenho aprendido que nós, brasileiros e brasileiras, somos um país oficialmente bilíngue, conforme o decreto da Lei no 10.436/2002, do ex-presidente Fernando Henrique Cardoso.

Aos poucos, vamos reativando a discussão sobre o ensino de história no Ines, onde conheço um novo público: os surdos e as surdas. Contudo, não na identidade de pessoas deficientes, mas como sujeitos com outras autonomias. Assim, introduzir, criar e pensar possibilidades com eles tem sido uma nova forma de construção de conhecimento. Sensibilidade, identidades e alteridades continuam conduzindo as reflexões e existências de minha prática docente.

Por fim, a estrada com a licenciatura em história permanece contínua e afetuosa por novos trabalhos e parcerias. Afinal, as práticas docentes são campos de experimentação, um continuum de tempo e afetividades.

\section{Referências}

ABUD, Katia Maria. A história nossa de cada dia. In: MAGALHÃES, Marcelo; MONTEIRO, Ana Maria; GASPARELLO, Arlette. Ensino de bistória: sujeitos, saberes e práticas. Rio de Janeiro: Faperj, 2007.

AMISTAD. Direção: Steven Spielberg. EUA: DreamWorks SKG, 1997. (155 $\min )$.

BITTENCOURT, C. O saber histórico em sala de aula. São Paulo: Contexto, 2006. 
CANCLINI, Néstor. Culturas hibridas: estratégias para entrar e sair da modernidade. São Paulo: Edusp, 2003.

CHEVALLARD, Yves. La transposición didactica. Argentina: Aique, 1991.

ELIAS, Norbert; SCOTSON, John L. Os estabelecidos e os outsiders. Rio de Janeiro: Jorge Zahar, 2000.

FANON, Frantz. Pele negra, máscaras brancas. Salvador: EDUFBA, 2008.

FOUCAULT, Michel. A escrita de si. In: FOUCAULT, Michel. O que é um autor?. Lisboa: Passagens, 1992.

FREIRE, Paulo. Pedagogia do oprimido. 8. ed. Rio de Janeiro: Paz e Terra, 2013.

GOIS, Diego Marinho de; SOUSA, Gustavo Pinto de. Balanços, comparações e sensibilidades: o lugar da Lei n. 11.645/2008 nas universidades públicas do Pará. In: SILVA, Giovani José; MEIRELES, Marinelma Costa. A Lei

11.645/2008: uma década de avanços, impasses, limites e possibilidades. Curitiba: Appris, 2019.

G.R.E.S. ESTAÇÃO PRIMEIRA DE MANGEIRA. Histórias para ninar gente grande. Composição: Tomaz Miranda, Ronie Oliveira, Márcio Bola, Mamá, Deivid Domênico e Danilo Firmino. Rio de Janeiro, 2019. Samba-enredo.

HALL, Stuart. A identidade cultural da pós-modernidade. Rio de Janeiro: DP\&A, 2002.

INVICTUS. Direção: Clint Eastwood. EUA: Warner Bros. Picture, 2009. (133 $\min )$.

JENKINS, Keith. A bistória repensada. São Paulo: Contexto, 2001.

KIRIKU e a feiticeira. Direção: Michel Ocelot. França: Artmann, 1998. (71 $\min )$.

LIBÂNEO, José Carlos. Didática. São Paulo: Cortez, 2013.

LIMA, Monica de Souza. Para que serve a história da África?. Revista História Viva, 2014.

LOPES, C. A pirâmide invertida: historiografia africana feita por africanos. In: COLÓQUIO CONSTRUÇÃO E ENSINO DA HISTÓRIA DA ÁFRICA. Anais... Lisboa: Linopazas, 1995. 
MACEDO, Manuel Joaquim de. Lições de história do Brasil para uso dos alunos do Imperial Colégio de Pedro II. Rio de Janeiro: Tipografia Imparcial de J.M.N. Garcia, 1861.

PESAVENTO, S.; LANGUE, F. Sensibilidades na história. Porto Alegre: UFRGS, 2007.

RÜSEN, Jörn. Didática da história: passado, presente e perspectivas a partir do caso alemão. Práxis Educativa, Ponta Grossa, v. 1, n. 2, p. 7-16, jul./dez. 2006.

SANTOS, Boaventura de Sousa. Para além do pensamento abissal: das linhas globais a uma ecologia de saberes. Novos Estudos Cebrap, São Paulo, n. 79, p. 71 94, nov. 2007.

SILVA, Petronilha Beatriz Gonçalves e. Aprendizagem e ensino das africanidades brasileiras. In: MUNAGA, K. (org.). Superando o racismo na escola. 2. ed. Brasília: Ministério da Educação/Secad, 2005.

SOUSA, Eveline Almeida de; GOIS, Diego Marinho de. Estudiantes indígenas en la Universidad Federal del Oeste de Pará (Ufopa), Santarém (Brasil): Waiwai, Arapium y Tupinambá. Boletín Americanista, Barcelona, ano LXVII, v. 2, n. 75, 2017.

UMA LIÇÃO de vida. Direção: Justin Chadwick. Inglaterra: BBC Filmes, 2009. (103 min).

UNIVERSIDADE FEDERAL DO OESTE DO PARÁ (UFOPA). Plano de desenvolvimento institucional. Santarém, 2012-2016.

UNIVERSIDADE FEDERAL DO OESTE DO PARÁ (UFOPA). Projeto pedagógico do curso de licenciatura em história. Santarém, 2017. 